\title{
About Testing, Tracking, and School Choice with Professor Adam Gamoran
}

\author{
David Greger, Jaroslava Simonová
}

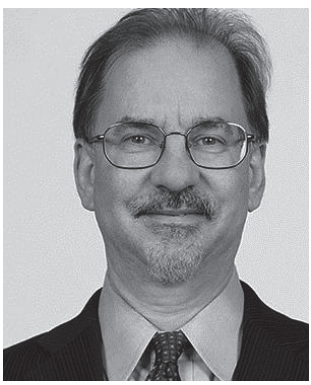

Professor Adam Gamoran is the president of the William T. Grant Foundation (http://wtgrantfoundation.org/whoweare). He came to the Foundation from the University of Wisconsin-Madison, where he held the John D. MacArthur Chair in Sociology and Educational Policy Studies. In a research career spanning three decades, Adam conducted a wide range of studies focusing on inequality in education and school reform. Among his major works were a series of studies on tracking and ability grouping that identified consequences for student achievement and revealed the mechanisms through which those consequences occurred. Subsequent studies examined interventions to improve performance and reduce learning gaps, assessed through large-scale cluster-randomized trials. He was a Fulbright Scholar in the United Kingdom. He is an elected member of the National Academy of Education and the American Academy of Arts and Sciences, and was twice appointed by President Obama to serve on the National Board for Education Sciences. As president of the William T. Grant Foundation, Professor Gamoran has prioritized supporting research to deepen our understanding of the programs, policies, and practices that reduce inequality in youth outcomes, and to understand and improve the use of research evidence in decisions that affect young people.

In 2013, Professor Gamoran received the Spencer Foundation Award for contributions to research on education policy from the Association for Public Policy and Management, and in 2014 he was honored with the award for Distinguished Contributions to Research in Education from the American Educational Research Association.

In May 2015, he was a key-note speaker at the conference "School tracking: diverse mechanisms, effects and policy responses" that took place at the Faculty of Education, Charles University in Prague. His presence in Prague was a valuable opportunity to discuss approaches to tracking, school choice and educational policy in general and ask him many questions from the perspective of a small educational 
90 researchers' community in Central Europe with its limited research funding and rather heated debate about equity and tracking. Nevertheless, we believe that Professor Adam Gamoran's deep insight might be an eye-opening experience and an inspiring reading also for many other readers of our journal. (The second part of the interview about the research-policy relationships and research funding in the United States will be published in some of the next issues of our journal.) The questions were asked by David Greger (DG) and Jaroslava Simonová (JS).

DG: In the first part of this interview, we would like to learn more about the recent trends and issues in educational policy in the United States. Before discussing the main topic our conference - tracking, I would like to ask you about the Common Core Standards. How come that so many states of the USA adopted a common curricular document, and why did some of them changed their mind recently?

AG: The reason that the states had adopted The Common Core State Standards was that the Obama administration made available huge part of money called Race to the Top, which was a part of The American Reinvestment and Recovery Act, which was as an economic stimulus that was passed and provided after the 2008 recession. It was a way to crop-up states when they were in economic crisis. So, a huge part of the money to be awarded to states competitively and in order to be eligible, the states had to adopt "college and career readiness standards". So, these Common Core State Standards were a way of doing that. That's why 45 out of 50 states adopted The Common Core.

Now, a few years later, the states have become more resentful, especially states with Republican leadership, and Indiana was one of them. So they say: "Federal government is not going to tell us what to do! No more Common Core State Standards!" Then, they just adopt the same thing and call it by a different name.

Another condition was that states would adopt assessments so they can hold schools, and in this case teachers, accountable for student performance relatively to standard. The administration - also as part of the same, big funding package awarded two 170 million dollar grants to two different consortiums, groups that were developing these assessments. One is called PARCC, which is something like Partnership for Assessment of Readiness for College and Careers. The other is called Smarter Balanced.

DG: What are the differences between the two? Are there any? Or why have some states chosen one and not the other?

AG: Partly marketing, one consortium might have been more successful with one state and the other with another state. There was more emphasis on a balance between focused knowledge and problem solving in the Smarter Balanced assessment. One of them was going to be more computer adaptive than the other. So there were some differences, but the overall philosophy of the two was the same, which is that they were going to be rigorous, they were going to be tied with The Common Core State Standards and they would be in-depth assessment, not multiple choice, but problem solving, constructive response... So they were 
supposed to be better assessment than were typically used by states to measure student progress first-hand.

JS: And the non-cognitive skills are not part of the assessment?

AG: No, not the non-cognitive skills... Good question though. And there is a discussion in the US about social and emotional learning and whether there should be deliberate instructional strategies for social and emotional learning, whether there should be assessment for social and emotional learning, but so far that's not -

DG: And does it actually follow the No Child Left Behind policy and try to react to the problems with different states using different tests to reach the proficiency levels?

AG: Yes, exactly, and different states holding different standards setting. So, when it comes to educational inequality - one of my interests - the big promise of The Common Core State Standards would be to reduce inequalities among states, which is rarely examined but major dimension of inequality in the US.

\section{The No Child Left Behind story}

DG: And is it a big problem, the inequality between states? If you consider that, for example, many students actually finish their tracks within the system because the tuitions are lower in the states, I guess, at state universities? So what's the main deal there?

AG: It is. Well at the K-12 level it is a big problem of inequality. And in some cases it was exacerbated, it was made worse during the No Child Left Behind era, because now states had to hold schools accountable for performance, so many states simply set a low threshold for performance, so they could say all those schools are succeeding. But No Child Left Behind caught them in the end, because even a state like the one I lived in for thirty years - Wisconsin - where they set a low threshold, for example, in Wisconsin about $80 \%$ of the students were judged to be proficient on the Wisconsin assessment, but if you look at NAEP - the national assessment and testing - only $40 \%$ were proficient. Why? Because Wisconsin set a very low threshold for what counted as proficient. But even in Wisconsin, eventually, all the schools would be failing. Why? Because No Child Left Behind set the impossible standards of a $100 \%$ proficient. Wisconsin schools were like an $80 \%$ proficient for the whole No Child Left Behind period, so for a long time they were doing very well, but even in Wisconsin they got caught in the end by the No Child Left Behind.

DG: And this is a good example for a link between policy and research... In a small country like the Czech Republic where we have no studies available, we - kind of are not surprised that our policy makers sometimes do very surprising things in our view... But when I read about the NCLB and about the $100 \%$ proficiency, I think many researchers were against it from the beginning, said it was too ambitious. So how could it happen, or how do you explain that fact - they didn't listen to researchers, or...? 
AG: Right, that's true. No Child Left Behind was the product of a rare compromise between the left and right - the Democrats and the Republicans - and one feature that got people on the left excited about No Child Left Behind was that all children will be helped to the same standards. There won't be lower expectations for kids who are disadvantaged or at minority backgrounds. So by saying that all schools will reach a $100 \%$ we're declaring that everyone will meet the same standards. Now of course that was widely unrealistic and I think at the time there was a thought that this is an aspiration, not a real goal, and as we get closer, we'll be able to demonstrate the progresses made, but not enough progress, and so we'll push the time period ahead. I think that was the thinking at the time.

Now, let me put a parenthesis on that and l'll come back to it. Why did the right favor a $100 \%$ proficiency? Many people have charged that the right wing favored the $100 \%$ proficient because they knew that all schools would be judged failing eventually and they could make an argument that said that all schools should be privatized and students should use vouchers and go to whichever school they want... So two different reasons for why this $100 \%$ proficient was picked.

The thinking was though, that - at least among reasonable people - that, well, in five years we are going to re-authorize No Child Left Behind and we'll reset the target, we'll know that the $100 \%$ is the aspiration but we'll keep moving up there. But by the time five years have passed the coalition that created No Child Left Behind had shattered. Senator Ted Kennedy died a little bit after that, and he was a very important part of putting together that coalition. The right and left had fractured over the Iraq war and other things going on in the US politics, so there was no way to re-authorize, and still now - it's 2015 - this bill was supposed to be re-authorized in 2007 and nothing's happened since then. (Editorial remark: On December 10, 2015, several months after this interview took place, the Every Student Succeeds Act or ESSA was signed by President Obama. ESSA replaced NCLB.)

So, even if people who knew what they were doing had an idea that would simply fix this in five years that was not able to happen. There's a researcher for example named Bob Linn from the University of Colorado, he wrote an article very early on showing that this was unrealistic and other flaws in No Child Left Behind, but that wasn't even part of the discussion, it was a political decision, it wasn't on research basis.

DG: But you say that even the politicians knew it wasn't an achievable goal...

AG: It's hard for me to say what politicians do, but certainly the staff knew that it wasn't. I gave a speech where I said "no school has ever made the progress that the typical school is required to make under No Child Left Behind. No school EVER has made the kind of progress that the AVERAGE school has to make!" I kept giving that talk over and over again and I was waiting for someone to show me a school that did make that kind of progress, so I could say "only one school or only three schools have ever made that progress", but l've never found one. 


\section{The Implementation of Common Core Standards}

DG: Well, we are now on the federal level and we certainly know that NCLB is a top-down federal level policy, but The Common Core Standards - is it top-down, is it federal level? Because I got the impression it's made bottom up by a coalition of states, but now you say it's linked to the resources from federal government...

AG: That's exactly right.

DG: So how would you characterize that policy?

AG: It's a clever combination of top-down and bottom-up. When the US entered an economic crisis in 2008, Congress has appropriated a lot of money to stimulate the economy. A portion of this went to the US Department of Education, about 4 billion dollars - small compared to the whole stimulus package, but huge for the US Department of Education. Secretary Duncan had more money to allocate - more discretionary money to allocate - than all previous secretaries of education going back to the beginning of the Department of Education. The biggest part of that allocation was a competitive grants program called Race to the Top. They were trying to incentivize states to improve their education systems. One of their conditions for being eligible to compete for Race to the Top was embracing rigorous standards created by a coalition of states or otherwise demonstrably being college and career ready. In response then the states created The Common Core States Standards and almost all states then agreed to aspire to and to implement The Common Core State Standards, so it was a bottom-up effort in response to a top-down incentive.

DG: And I have read that some foundation just evaluated the standards at individual states and compared them to new Common Core Standards and they show that it's really like growing, more demanding standards being applied nowadays. What could it mean for the test-based accountability at state level? And actually when you introduced such a new standard and students are already in school, when should they be eligible for testing etc., should there be some time maybe between the introduction of standards and testing?

AG: Well, those are good questions. Let me say first step - research played an interesting role in the development of The Common Core State Standards. Of course there is a research base for saying that setting higher standards promotes higher performance - it won't surprise you to hear that, I am sure - and some researchers working with a grant from our foundation, Lorraine McDonnell and Stephen Weatherford, investigated the extent to which research played a role in the development of The Common Core State Standards. Advocates wanted the standards to be based on research, but knew that the research was insufficient in about itself and so they tried to pull together research and other types of evidence, for example the wisdom of an experience, feedback from teachers unions etc. So the research was used in the development of The Common Core Standards to frame the issue, to make the case that higher standards will promote higher performance, and in some cases to develop an approach to standards, particularly this idea of learning progressions 
94 that now accumulates and that students can go through a well-defined progression over time, although they didn't have research to identify with what the progression should consist of all the way through. So research was used to frame, to give direction, and then had to be filled in with a lot of other types of knowledge.

DG: So it means the schools have to use it from the year they were adopted and the testing would follow? Because here for example we have time to time discussions, for example now the discussion in the Czech Republic is that we don't have national testing. We have some now, and the only real national testing is the final upper-secondary leaving examinations, like examinations from high school that is now standardized through tests, it's kind of a recent development...

AG: Oh, really?

DG: Yeah, so the Czech Republic had no accountability at all, no national test. And no test-based accountability for sure, also there is a big opposition from our side, we are skeptical it could work. And especially in the Czech Republic you should understand the knowledge of testing, we still use classical test theory, we don't use IRT etc., we don't even publish the results and analyze them in a correct way, so you should understand there's a low capacity for doing good research and good tests. If then you assign big consequences or stakes to such tests, we are rather saying we are not sure...

But to go back to the argument - now the discussion is that the minister proposes that math should be an obligatory subject to take in the final exams, and long discussion goes around that if we think the math should be obligatory, already students entering high schools should know it and be prepared for it. So you could not introduce it earlier than five years on, you have to prepare the standards, but you need to have five years time so that students entering the schools could prepare for such the final exam... I wonder if such a discussion appeared on The Common Core?

AG: Sadly, political impatience prevented that wise course from being implemented. What you described would be a much more sensible process. Creating a time period to become prepared, to teach the standards and for students to respond to the standards, but that isn't what happened - the political cycle is far too short for that. The idea was that in one year the new assessments will be pilot-tested, the next year they will be implemented and that's it. Teachers would be responsible for teaching it, schools would be responsible for supporting it, students would be responsible for performing. And of course that was unrealistic, but another feature of the federal policy under the Obama administration would be less emphasis on performance at a single point in time and more emphasis on growth, on improvement in performance over time.

So my feeling at the time this policy was designed was that it was not a weakness, that it was OK to implement the tests immediately because you were just establishing a baseline, and then you would see progress over time and in fact credit would be given to schools and teachers whose students improved over time. And that would be a great way to show progress, to give credit for the hard work of implementing and learning the new standards, teaching the new standards and performing the new 
standards. So that didn't seem like such a bad idea to me. But, unfortunately, there is not enough understanding of the distinction between performance or status at a given point in time and growth. And this misunderstanding was reinforced by No Child Left Behind which had no concept of a growth, it was all about performance at a single point of time. So the innovation of the policy under the Obama administration to focus more on growth was lost and teachers were horrified at the idea that they would be held accountable for standards for which they had barely been introduced, let alone prepared to teach to.

\section{The issue of teachers' accountability}

And there's another thing that happened in a federal policy in the US that made this even more difficult, and that is the Obama administration implemented, or rather among the criteria that states had to follow also to be eligible for Race to the Top, was not only holding schools accountable for students' performance, but also teachers. And that was new, under No Child Left Behind there was no teacher accountability, only school and district accountability. But under the Obama administration's policy it was the teachers as well. And we are not very good at using test scores to evaluate teachers. The measures are too imprecise, there are too few data points... Two ways of saying same thing. So this was problematic.

There's been such a negative response to holding teachers accountable with the use of tests that it has pushed aside all the benefits that have come along with it - more rigorous standards, deeper assessments and the focus on growth. Which I think are three big improvements that the Obama administration brought, and yet all have been lost because of the emphasis of the teachers' testing and because of the failure to do what you described they did here, which is they implement it in a more gradual way.

JS: And how did parents react? They are also stake-holders.

AG: Yeah, many parents were not that knowledgeable or engaged or familiar, but the ones that were initially tended to be supportive, because they liked the idea of more rigorous standards, and they liked the idea of teachers being held accountable for producing. But there was always a current of suspicion among some parents over the idea that standards from Washington would be imposed on their district, even though The Common Core State Standards and the assessments were state initiative, not federal initiative, nonetheless, as I have described... Well, it's kind of federal. Anyway, they objected that. But for the most part parents were favorable, or if they were engaged at all they were favorable, for the most part.

But because of the backlash against holding teachers accountable, parents have been whipped up into a frenzy and there are many parents who oppose assessments. And there's something going on now in the US called "Opt-out" - the parents can withhold their students from having taken the test. It's not all over the country, but in some places it's very concentrated and so if parents are withholding their kids 
96 from taking the exam in any kind of numbers, then you don't get the results that meaningful, because this is not just about one kid's performances, it's about the school and the teacher.

DG: And they couldn't be forced to take the exam.

AG: Right, yeah.

DG: So then the biggest opponents were probably the teachers unions?

AG: Absolutely.

DG: Were they influential enough to stop it? What's the future of teacher effectiveness and even teacher pay-performance schemes or all these measuring via tests, the teacher effectivity?

AG: I would say that for most of the period we've been discussing it, since the beginning of No Child Left Behind in 2002 through the election of president Obama and his administration to today, 2015, for most of this period I would say teachers unions were ineffective. Teachers unions favor high standards, but they are not big fans of high stakes testing and they certainly opposed holding teachers accountable for student performance. And after all we had a Democratic president. The Democrats and the teachers unions are natural allies - but nonetheless the policies implemented by the Obama administration were vigorously opposed by teachers unions without success. Only in the last two years I would say, the teachers unions have gained traction in rallying opposition to the new test. And, as a result, there's a wide spread opposition to The Common Core State Standards even though it is not really the standards they're against, it's the tests tied to the standards, but they tend to conflate the two.

DG: Well, it now reminds me of some opposing researchers we use on teacher effectiveness measures like Richie Ingersoll from University of Pennsylvania who would say "you wouldn't find another profession that would be held so accountable", which shows that the teaching profession is semi-professional and they are not trusted to do their work well. But on the other hand when I heard the interview with Stephen Ball from UK, he argued that - and I don't know whether it was the case for UK or the United States - that nowadays even surgeons and medical hospitals are held accountable and that it leads to some side-effects, or not desirable effects, that they are not taking patients for treatments that are hard to recover, or if there's no chance to solve their medical problems, that they are sending them to another medical hospital, saying that they would disturb their statistics and effectivity. Do you see any similar side-effects? Or what would you reply to that criticism?

AG: Well I have always been a fan of experimentation with teacher accountability. I think there is much to be learned and I thought that by collecting data over time and aggregating that it would be possible to get precise enough measures of teacher contributions so that at least the teachers who are very poor performers could be identified and given a chance to improve and then if not improve, then go find another job. So I've always thought that we should experiment with that, but I would never have imposed it on such a wide scale - in fact I had a chance to talk with secretary Duncan and his cabinet and that was my advice, that it shouldn't be imposed on such a wide spread basis, because it wasn't ready yet. 
But I've thought that the idea that you can monitor students' growth and achievement from one year to the next, if the measures were precise enough and if the sample were large enough, that it could be informative. So, are there negative side-effects? You know a lot of people complain about teaching to the test. My view has been - if it's a good test, it's worth teaching to. And this is how I view the new assessments developed in response to The Common Core State Standards. This is the first year they have been implemented so it's a little too soon to say but my hope is that they will be rich assessments that provide positive incentives for teaching about things that matter and in ways that develop students' minds and not just raw memorization of knowledge.

So I think it's possible to avoid many of the negative consequences. Another negative consequence that people are concerned about is cheating. And of course there is an incentive to cheat which is then a huge scandal with people going to jail, going to prison for ten years - in Atlanta over a cheating, what the jury found to be a conspiracy to cheat. So, yeah, there is an incentive to cheat when there are high stakes but I don't think that's a reason to not impose accountability.

The reasons not to impose teacher level of accountability too far - the reasons not to do it - one: the measures are not precise enough, and two: it turns out that teachers are not largely motivated by money. You mentioned Ingersoll before and he has shown this. Teachers are motivated by working conditions more than by money. The pay-for-performance experiments have failed in the United States, so I think we know enough to know that that's not going to work.

\section{The incentives alone are not enough}

DG: But at the teacher level it seems to me even more strange idea, because methodologically it is much more difficult to really get the teacher evaluated as the impact of previous teacher and a lot of other stuff we could not really wave out from the analysis. But even test-based accountability initiatives at the state level seem not to work.

I've read The Incentives and Test-based Accountability in Education produced by National Research Council and the argument is that the effect size is around .08 standard deviation, so all the programs implemented in past in the US have in their conclusion no effect, like .08 is no effect.

But still there is a movement and belief that we could do it and it turns to the discussion whether the strategy to blame and shame schools that they are not doing their job well, and teachers, whether you see that as a promising way forward? So is it only a technical issue, that we should do better tests, better standards - as I understand is now the development in the US - or whether it's maybe your own direction, what Stephen Ball would argue, performativity...

AG: Yeah, I think you have identified the policy alternatives correctly for the US... There's some controversy over whether test-based accountability has had a small 
98 effect or no effect, but there is no controversy that it has not achieved the benefits we had hoped for, that's clear. You know, No Child Left Behind was not only a system of accountability, it also contained specific research-based approaches that would lead to better performance. Placing a highly qualified teacher in every classroom, one-on-one tutoring for struggling students, choosing instructional methods based on research evidence - those were the three research-based strategies that were part of the No Child Left Behind. There was a fourth strategy - school choice, which I would say the research is not supportive about, but that was in the No Child Left Behind also. But what I and my colleagues found in a book that I edited in 2007 was that these strategies were implemented so weakly and so inconsistently that there was no chance that the strategies for improvement could succeed.

So it seems clear that the incentives alone are not enough, that you need the resources and strategies to improve, and the strategies need to be implemented. But I would argue that the incentives provide a baseline for taking on those strategies.

With some colleagues I wrote a book in 2003 about how schools and school districts can support teachers who want to improve their practice. A big limitation in that work was only a small minority of teachers were included in the group who wanted to do something about improving their practice, because for most teachers there was not an incentive. The incentive is to do what you did last year. And the accountability system gives teachers an incentive to improve their practice. And in fact a study by RAND found that the biggest consequence of test-based accountability system was that teachers agreed with the statement "I'm trying to find ways to raise student achievement" or something like that. So there is a perception that we need to get more learning out of our students. At least you bring people to the table, you set them up for being open to new ideas and approaches that might raise student performance. Then you have to deliver the goods, then you have to provide the new directions and provide the supports to learn, to teach towards those new directions. And that was a complete failure under No Child Left Behind.

\section{Good ideas, questionable implementation}

DG: I think what you said about the problem with implementation is very typical here. Sometimes we don't even see trials and no plans for implementations and whatever. But even with - and I see it as a good and research-based strategy - placing highly qualified teachers in every classroom, l've also heard about problems with implementation actually raising an inequality, because I've read a study that shows that in some parts of California the poor districts could actually not hire science and math teachers in the US because there was unequal funding based on the city tax in the US for schools, so they were unable to find teachers and there was no state support to really get the qualified teachers in the poor or remote areas and deprived schools etc.... There was a colleague from California who described how - and they had to solve it based on a law - they were inviting teachers from Philippines who 
had good English, math as major etc., but in front of the US classroom in very poor

suburbs they were horrible, they used to be teaching fifty kids and when they saw these kids they said "they are not poor kids, they are very wealthy" etc. Maybe this is very marginal scale, but -

AG: No, it's not marginal at all, it's a major problem.

DG: So did it really solve the inequality problem with the schools where the staffing is the problem?

AG: No, it certainly did not, this is one aspect of what I mean by failure to implement. With respect to highly qualified teachers there were a lot of problems with what seemed like a good idea. First of all, what counted as highly qualified was you have a B.A., you have a teaching certification and you have expertise in your subject matter.

Now of these three it was the expertise in your subject matter which was the innovation. But states varied widely in what that meant. In some states, teachers had to take a test to demonstrate their knowledge, in other states they had to have a college degree in the field they were teaching, in other states they simply declared all of their teachers to be competent - if you're a math teacher, therefore you know math. So it wasn't implemented in a consistent way. And then, as you say, the resource base differs across school districts. It's a profound dimension of inequality in the US and so if the districts can't compete for the same teachers, then you end up with a lot of inequality across districts, even within the state, let alone across states where there are huge differences, huge disparities in education spending. So yeah, you're absolutely right, it didn't solve the problem because it was not implemented in a way that could have possibly addressed the problem.

\section{Tracking, de-tracking and school choice}

DG: We are too much in the NCLB - it's interesting, but maybe to go back to the general questions. I will maybe use another example which you are an expert on as well, and that is tracking. So would you say that the de-tracking reform was reacting to research findings? And what's the result of that? So let's have another example, I had the third one prepared at a school choice, that would also be the critical question of Stephen Ball and the others, saying - and you confirmed it - that this is not a research based strategy to enhance the student learning, rather to enhance inequalities, but still policy makers are going in that direction. So before tracking, how did -

AG: Well let me say a couple more things about school choice and then l'll talk about tracking. School choice is a great example of the interplay of the difficulties, of the interplay between research and policy - at the policy level in the US at the federal or state levels. A great example, because here you had an idea that did come out of research. There were research-based theories going back to the work of Milton Friedman, but also John Chubb and Terry Moe and other writers as James Coleman, the great sociologist, writing about why having students choose schools 
100 should increase student performance. So that was the theory, and to the extent that this became part of the policy there was a relation between policy and practice.

The breakdown is that the evidence did not support this, the evidence for the benefits of school choice is very weak. There is some evidence of positive effects, another evidence of negative effects, but it's very weak. Especially for a private school choice. But when it comes to public school choice the interest is in charter schools in the US and here too the main finding is the effects of charter schools are variable, some outperform the schools that they're drawing students from, but others perform worse. So not a strong evidence base for promoting the policy.

Nonetheless it's a favorite of Republican politicians because of their ideological commitment to market-based solutions and lack of appreciation for the failure of markets in the public sector. It takes information to make a good choice, right? But information is unequally allocated. In order to encourage choice, schools spent resources on marketing themselves. Those are resources that could have been spent on the education program. These are all research-based findings that demonstrate the reasons for market failure and yet those don't enter into the conversation because of the ideological commitments of the politicians who favor them.

Tracking is a different kind of example. I would say yes, the research on the negative effects of tracking did play a role in the de-tracking movement, which was by the way not a federal policy movement, for the most part not a state policy movement, it was a policy at the district level and school level. So decisions about de-tracking occurred at the district level or the school level, not the state level.

DG: Are there some districts that didn't implement de-tracking? Like in the UK there was a movement for comprehensive national reform which was also left on the individual local education authorities, until nowadays they still have some grammar schools operating on a very small scale, like $4 \%$ of kids. How is it in the US?

AG: Yeah. At the surface level there is some comparability, only in a sense that there is variability among school, but the dynamic was quite different, because in the UK you had a national reform comprehensive, with many schools maintaining the prior approach and also the reform being phased in, so different schools would become comprehensive at different points of time. There was nothing like that national policy in the US. Instead you had specific districts adopting or recognizing the negative consequences of tracking and adopting de-tracking reforms, very often lead by teachers - not always, but very often. Very often provoking some hostility or controversy among parents, especially parents of high-achieving students who wanted their kids in the advanced classes.

So it was a district or even school by school initiative, there was no top-down component as in the UK. And as a result, overwhelmingly school districts in the US have continued to use tracking and ability grouping. Very few schools have the kind of broad, curricular tracks that might have been more common in the 1950's and 60 's, for the most part it's subject by subject grouping, it's not tracking for all subjects. But almost all districts have some kinds of ability grouping in some subjects, so that's another big difference to the UK. 
Anyway, I would argue - without having done the research myself, but just having lived in this world - that the research evidence on the negative consequences of tracking did play a role in the decision that many school districts tried to reduce the use of tracking. But it's a selective reading of the evidence.

As I've argued in my own writing, advocates and critics of tracking look at the same studies, but don't read the same things and they talk past each other. Critics of tracking emphasize that tracking exacerbates inequality, which it does. Proponents of tracking emphasize that it promotes the achievement of the highest achievers, which it also does. And the critics of tracking who were implementing de-tracking didn't deal with that aspect, didn't deal with the consequences for high-achievers, they just asserted that de-tracking will benefit everyone and there are number of cases where that hasn't been the case. That's one of the reasons that the de-tracking reform I think installed.

JS: I would like to go back to school choice. In the Czech Republic the school choice is not the issue of school effectiveness or better achievement, but an issue of parents' freedom to choose a school. How could we argue with such an argument?

AG: I think that's a much better rationale for school choice than student achievement, because what we find is that student achievement is not substantially different among kids who have used a voucher and is not consistently different among kids who have made a choice to go to one school versus another competitive students who want to make the choice but don't get the chance to because they didn't win the lottery for whatever reason.

But that doesn't mean that it's not a place where the families are more satisfied or where students are being taught in a way that aligns more with their parents values. In fact there's some evidence that says that even though there is an absence of effects on achievement, there are higher levels of parents' satisfaction when kids go to the voucher schools or the private schools of choice. So that would be very consistent with what you're suggesting.

Now whether that is a good thing or a bad thing depends on your perspective about the parent freedom. Education plays an important role in promoting shared values and in creating a coherent and unified society and if we differentiate among schools in a way that leads kids from different backgrounds or different religions or different ideological preferences to go to different schools, then we don't have that opportunity for creating connections across different parts of society. It's like Durkheim's organic solidarity, you don't have the chance to build those ties of organic solidarity if you never come into contact and you have no co-dependencies with people from other origins. This is a matter of values rather than of scientific findings or evidence I would say.

JS: But don't you think it could harm children from not-so-good backgrounds?

AG: If the system of choice is set up that they don't have the opportunity to choose the schools where kids from more affluent backgrounds are found. Coleman's idea, or the reason he favored school choice, was because he thought in the system we had children from disadvantaged backgrounds are not able to go to 
102 schools with more affluent peers because they are in impoverished neighborhoods, and if school tendencies are determined by where you live, then you have that kind of economic segregation. Whereas a school choice program would allow you to go to school you have selected irrespective of where you live. Coleman's idea at least was that that's exactly the point of school choice, it does allow you to do that. If you lack resources but you're in a market place for schools, you can send your kid to the school where it can be best served.

DG: But Coleman's rationale was far away from rationales in our country. His rationale was to make schools more diversified and allow more of the less favorized to be with more affluent families together. But here it's like “Ok, you shouldn't limit anyone's choice" and we know the end in the Czech Republic is that we have very affluent schools or schools with people from very affluent families and schools in deprived areas and even now ghetto schools like Roma schools, because once you have more Romas in school the white people, the majority, leave that school and the policy makers are not willing to change the catchment areas in a way that the Roma children would have a right to enter any school around. So it is rather a school choice for those who are using it and those who more influence voting and policy so more educated parents and middle class.

AG: Yeah, this is an example of what I was speaking about before, about the failure of the markets and the public sector. If there is unequal information or unequal access to power then the choice system might promote more divisions instead of being for a free equalization, yeah...

JS: And could we prevent it?

AG: In principle it could be prevented but one thing we find in public policy is that the advantaged families seem to find ways to take advantage of public policies, to use public policies for their interests... So in principle it could be prevented.

\section{Resources trump choice}

DG: There's actually a big discussion - or our discussion, it's not big, but our national discussion - what would be good for the Czech Republic. Because since we have had communist system we don't have segregated living. We have many people from very different social strata living next to each other. But now more and more the educated parents choose better schools and even pay for private schools etc. So to support equality in the system we would vote for introducing catchment areas not allowing educated parents to go out of their areas. But then we had a discussion that it would probably lead to what happened in the United States, the residential differences because then the prices of the flats... But some people still would argue "well, it will take some time, maybe seven, maybe ten years, so the catchment areas could have some influence on equality"...

JS: So the question is more general. How to make school more heterogeneous, not just by catchment areas, but are there any other measures? 
AG: Well we've tried this a lot in the United States and it has not been very successful... I have a new article coming out in Educational Evaluation and Policy Analysis focusing on Nashville, Tennessee, which is one of these districts that had court imposed desegregation, they had a very complicated busing system... There's a longer story. In 1954 the Supreme Court decided that segregation was illegal. Well it took about thirty years for Nashville to finally agree, or to finally implement a true desegregation system. And they had a very complicated system of busing where students were moving all around town to create more diverse school populations. And it only lasted in fully implemented way for about a dozen years. There was a wide spread dissatisfaction even among the African-American community because of the substantial burden of busing. We have achievement data from before, during and after the court imposed desegregation and then the release of court imposed desegregation. Of course the schools became more segregated because students began once again attending schools closer where they lived - where they lived segregated, so the schools became more segregated. And what we found was that: On anticipating this the Nashville school districts designated some of the schools that were going to have the highest concentration of low-income African-American families as what they called Enhanced Options Schools and they would get a lot of extra resources, they would get a longer school day, longer school year, smaller classes, after-school tutoring and social services. What we found is that first of all increased racial segregation did not change students' achievement trajectories, but an increase of concentration of poverty was a negative, but these enhanced option services counter-balanced the negative effects of increased poverty concentration. So the resources available to the school and the way they were implemented was more important than who you were going to school with. I had a line in a paper that the reviewers maybe take out, they said it was too strong for the evidence, but I said "resources trumped who you went to school with" or something like that, "resources were more powerful than composition", that's what it was. "Resources trump choice."

\section{Challenges to de-tracking}

DG: Another problem what I heard you say, and correct me if I understood it wrong, is that even for de-tracking there was a support of parents and schools etc. Also probably for these desegregation movements there was a support of general public opinion, that it was the right thing to do. That's the opposite in our country, maybe going back to communist idea, that equality is a communist idea, and you shouldn't limit the pupils freedom etc., so there's a big opposition of educated parents to de-tracking, opposition to policies against inequality or even to supporting deprived families and less educated parents. Is my evaluation of the American situation correct? How did it come, was it always so that the parents supported, let's say, measures for African-Americans and desegregation movements, or how could you change the view, if there was some change in public opinion? 
AG: First of all to respond at a general level, it's a matter of preferences and values, educational programs respond to different values and I don't think a social scientist is the one to say "we should value freedom more than we should value equality". Instead I think we should say "Ok, if you are going to promote a policy because it advertises freedom, here's what you can do to minimize the harm to the equality", or "if you're going to promote a policy that advertises equality, here's what we can do to minimize the harm to freedom, or to maximize freedom given the policy that advances equality". That would be my general response. With regards to the specifics here, there are always a variety of responses to any of these kinds of policies. I think Jeannie Oakes, with respect to tracking, has done an excellent job of diagnosing the challenges to de-tracking. She says there are political, normative and technical challenges to de-tracking. Political objections - some people have an interest in maintaining tracking, teachers who teach high-achieving students, parents of high-achievers who want them to be in high-track classes. Second, normative - we believe that people differ, it seems normal that they should be in different classes because they differ from one another, and overcoming that normative view can be a big challenge. But there are also technical challenges. It is not easy to teach students with widely varying levels of prior preparation. I think that with Oakes and people who have followed her, there's been an insufficient appreciation for the technical challenges of instruction of students with widely varying levels of prior preparation. I think that the technical challenges of de-tracking are perhaps more important than some people recognize.

DG: What I like about the US case is that you are trying to do something to make the society and education more equal. It seems to me that we are not really trying here to do something. And the result is that very often it is inefficient, because the parents find their own ways to do it. I think also the evaluation of the de-tracking reform is kind of skeptical from Samuel Lucas etc., who say that maybe the inequalities have become more invisible rather than disappear by this policy. What would be your evaluation of that?

AG: I agree with that, I think that is correct, specifically with regard to tracking. Even in systems I found, or at least even in systems where parents or students choose their own track levels it tends to resolve in the same thing, because they get advice from teachers, "you should choose this track". And so many of the changes have been illusory, they have been illusions and the inequalities persist. I think Lucas is correct when he identifies effectively maintaining inequality as a process whereby you minimize inequality at one level and it pops out somewhere else. That's a function of our larger system which is competitive, which has inheritance, where the reason parents try to accumulate wealth and power is so they can pass on those advantages to their offspring while they're alive and after they're gone. So you're swimming up stream trying to promote equality in a system where having wealth and power gives you a position of advantage. Someone said about democracy that it's a terrible system, it's just better than all the other systems, so, you know, there's something to be said for that here. 